\title{
Desenvolvimento de Prática Formativa para o Letramento Digital Crítico e Investigação de seus Efeitos em um Grupo de Licenciandos em Química
}

\author{
The Development of a Formative Practice for Critical Digital Literacy and an \\ Inquiry into its Effects within a Group of Pre-service Chemistry Teachers
}

\author{
Bianca Damas Pereira' \\ Paulo César Pinheiro ${ }^{1}$ \\ 'Universidade Federal de São João del-Rei, Programa de Pós-Graduação em Educação, São João del-Rei, MG, Brasil. \\ Autor correspondente: pcpin@ufsj.edu.br
}

Resumo: Esta pesquisa aborda a investigação de uma intervenção didática sobre letramento digital realizada na formação inicial de professores de química. Os licenciandos interagiram com mídias digitais pré-selecionadas, antes e após a apresentação do modelo teórico adotado. O objetivo foi analisar os efeitos da intervenção para o letramento digital crítico e a pergunta de pesquisa definida foi: quais são os efeitos do modelo e que outros aspectos emergem da prática formativa proposta para o letramento digital crítico dos licenciandos? A intervenção gerou trocas, questionamentos, reflexões e autorreflexões sobre a abordagem das mídias e o modelo agiu como um suporte para aguçar a percepção de suas características operacionais, estruturais, estéticas e éticas, bem como desenvolveu a criticidade e promoveu processos de significação mais íntegros. Apesar de ter ajudado a organizar o conhecimento para o letramento digital, aumentando o interesse e guiando uma análise mais crítica, os licenciandos consideraram o modelo complexo.

Palavras-chave: Letramento digital; Ensino superior; Formação docente; Prática formativa.

\begin{abstract}
This research deals with the inquiry of a didactic intervention on digital literacy carried out in chemistry teachers' pre-service education. The academics interacted with pre-selected digital media, before and after the presentation of the theoretical model. The aim was to analyze the effects of the intervention for critical digital literacy, and the research question was: what are the effects of the model and which other aspects emerge from the formative practice for critical digital literacy of the pre-service teachers? The intervention allowed for exchanges, questions, reflections and self-reflections about the media were approached, and the model acted as a support for sharpening the perception of its operational, structural, esthetic and ethical characteristics. It also developed criticality and promoted more complete signification processes. Even though the model helped organize knowledge for digital literacy, increasing interest and guiding more critical analysis, the pre-service teachers considered the theoretical model complex.
\end{abstract}

Keywords: Digital literacy; Higher education; Teacher training; Formative practice.

Recebido em: 10/04/2019

Aprovado em: 15/09/2019 


\section{Introdução}

No campo da Educação são desenvolvidas diferentes abordagens de estudos sobre tecnologias digitais e formação docente. A Lei n 13.005, de 25 de junho de 2014, que aprova o Plano Nacional da Educação (PNE) (BRASIL, 2014), em sua meta de número 15, garante a formação específica em nível superior, nos cursos de licenciatura, aos professores de educação básica. A sexta estratégia para essa meta aponta a incorporação das modernas tecnologias de informação e comunicação à formação na área do saber e das didáticas específicas, em articulação com a base nacional comum dos currículos da educação básica.

Riedner e Pischetola (2016) questionam como é possível que os professores estejam preparados para trabalhar com as tecnologias se não houver essa discussão no currículo. Também observam que elas são mais utilizadas fora das salas de aula e em pesquisas, e que são poucos os componentes curriculares que contemplam seus usos no ensino. Freitas (2010) também constata essa ausência e falta de integração curricular na formação docente, identificando maior preocupação com a tecnologia do que com o letramento digital. Na mesma direção, Buzato (2006) destaca a importância de se criarem metodologias e comunidades de prática, em que os formadores sejam mediadores e que haja colaboração.

Ribeiro (2016) reflete sobre o que aproxima o docente das tecnologias digitais, apontando seis elementos: a vontade de aprender, usar, relacionar, experimentar, avaliar e administrar o tempo. Esses autores apontam para necessidades na formação inicial de professores, por compreenderem que é onde se inicia esse processo. Professores capacitados e habilitados para utilizar as tecnologias digitais buscarão formas de aprimorar suas práticas educativas, cabendo, então, refletir sobre o papel do letramento digital.

\section{Letramento e Letramento Digital}

Durante muito tempo, a pedagogia e a psicologia se interessaram pela forma como as pessoas aprendiam a ler e a escrever, até que especialistas de outras áreas, como da linguística e da antropologia, passaram a pesquisar o assunto. Os estudos em antropologia eram denominados New literacy studies, os quais foram traduzidos no Brasil como novos estudos sobre ou do letramento, e o termo literacy ficou conhecido como letramento (CORRÊA, 2017).

Na década de 1980, o letramento surge como prática social a partir dos estudos liderados por James Gee, Brian Street e David Barton. Esse movimento foi criado em meio a uma mudança que ocorreu nas últimas décadas, na qual o foco dos estudos passava do individual para o cultural e social, ou seja, o letramento, que era um fenômeno cognitivo na abordagem psicológica, passou a ser considerado um fenômeno sociocultural e, por isso, os contextos tornaram-se relevantes. Assim, surgiu a visão de que ler e escrever envolve estudar o contexto social, cultural, histórico, político e econômico dos quais fazem parte (GEE, 2000). Segundo Barton e Hamilton (2004, p. 109), "[...] como toda a atividade humana, o letramento é essencialmente social e se localiza na interação interpessoal".

Os estudiosos defenderam que não há neutralidade no letramento e reconheceram as relações de poder imbricadas em suas práticas. Eles caracterizaram o letramento como prática social estabelecida a partir de eventos mediados por textos escritos. Surgiram então os conceitos de "eventos letrados" e "práticas letradas", os quais se tornaram instrumentos 
e unidades básicas de estudo. Heath (1982 apud STREET, 2004, p. 94, tradução nossa) mencionou que evento letrado é "[...] qualquer ocasião em que um texto escrito é essencial para a natureza das interações dos participantes e seus processos interpretativos", ou seja, o texto media uma atividade social. O evento surge da prática e é definido por ela, a qual compreende "[...] um conceito mais amplo, mais abstrato e refere-se tanto ao comportamento quanto aos conceitos relacionados ao uso da leitura e/ou a escrita" (HEATH, 1982 apud STREET, 2004, p. 94, tradução nossa). Assim, tem relação com valores, atitudes, sentimentos e relações/normas sociais que regulam a distribuição, produção e acesso aos textos.

De acordo com Soares (2002), no Brasil, a palavra letramento foi inserida inicialmente pela pesquisadora Mary Kato e adotado posteriormente por Leda Verdiani Tfouni e Ângela Kleiman. Soares (2002, p. 44) definiu o vocábulo como um "[...] estado ou condição de quem interage com diferentes gêneros e tipos de leitura e de escrita", com as diferentes funções que desempenham na nossa vida, e envolve "[...] numerosas e variadas práticas sociais de leitura e de escrita".

Atualmente, as pessoas, cada vez mais, leem, escrevem e atuam nos espaços possibilitados pelas tecnologias digitais. Há interações nas redes sociais, no envio de mensagens, na busca por informações, entre outras, utilizando recursos variados em suportes como computadores, celulares, laptops e tablets, por exemplo. Isso sugere a necessidade de desenvolver conhecimentos para leitura e escrita nos meios digitais, bem como para refletir, criar, compartilhar e agir nas práticas sociais transformadas ou criadas pelas tecnologias digitais. A partir disso, é possível pensar também em práticas e eventos letrados no universo digital.

Segundo Dudeney, Hockly e Pegrum (2016, p. 17), os letramentos digitais são "[...] habilidades individuais e sociais necessárias para interpretar, administrar, compartilhar e criar sentido eficazmente no âmbito crescente dos canais de comunicação digital", não só para enriquecer a aprendizagem em sala de aula, mas também para participar no mundo fora da escola. Eles agruparam os letramentos digitais em quatro focos: linguagem, informação, conexões e (re)desenho.

O primeiro focaliza as habilidades de compreender e criar textos diversos, seja de forma impressa, na internet, em hipertexto (hiperlinks), multimídia (imagens, sons e vídeos), nos jogos, no uso de internet móvel e na criação de softwares e canais de mídias (codificação). No segundo foco (informação), as habilidades são: interpretar e criar recursos on-line retratados como nuvens de tags, utilizar recursos de busca e compreender suas funções (pesquisa) e avaliar dispositivos e recursos, questionando criticamente, avaliando a confiabilidade, origem e credibilidade. As habilidades do terceiro foco (conexões) abarcam o letramento pessoal, em rede, participativo e intercultural, as quais envolvem: formar e projetar a identidade on-line utilizando ferramentas digitais; gerenciar redes on-line pessoais e profissionais para filtrar e acessar informações; comunicar, informar, colaborar, influenciar e criar reputação; colaborar com a inteligência coletiva das redes e interpretar recursos e dispositivos originários de contextos culturais variados. O quarto foco trata da habilidade de reutilização de conteúdos, dados ou obras, com intenções diferentes daquelas para as quais foram criadas (letramento remix).

Assim, o letramento digital inclui não somente a habilidade de interagir com as tecnologias digitais, mas também ler, escrever, selecionar e avaliar as informações nesses meios. Para Coscarelli (2016), isso depende da vida de cada indivíduo e envolve aquisição e uso de conhecimentos, técnicas, atitudes e qualidades pessoais e a capacidade de planejar, 
executar, avaliar e refletir sobre as ações digitais nas atividades diárias. Da mesma forma que o "letramento" é complexo, possui variações e gera disputas, é assim também na definição de "letramento digital" e derivações associadas.

Para Hinrichsen e Coombs (2013), as percepções das tecnologias se dividem geralmente entre uma visão neutra e outra que considera o aspecto social e suas interferências na política, nas práticas e nos currículos. Assim, há o eixo do determinismo tecnológico, uma posição mais ligada ao viés da neutralidade, que aborda o uso positivo e negativo das tecnologias e considera seus impactos universais. Essa perspectiva se relaciona ao avanço das tecnologias na medida em que afirma que devemos nos adaptar a elas, uma vez que, por existirem em constante evolução, apontam para o "perigo" de nos desatualizarmos.

O outro eixo é o do determinismo social, o qual considera que as tecnologias não são neutras, pois são moldadas e influenciadas por fatores políticos, econômicos e socioculturais. Dessa forma, ao 'ler' essas tecnologias, as influências podem se tornar mais explícitas. Assim, passa-se, por exemplo, a atentar mais para o que está sendo consumido. Essa oposição entre determinismo tecnológico e social divide os teóricos e os estudos de letramento entre a perspectiva funcional e crítica e as posições autônomas e ideológicas.

Em um projeto de mapeamento curricular dos letramentos digitais no ensino superior no Reino Unido, esses últimos autores constataram a predominância de abordagens funcionais que focavam nas ferramentas utilizadas e nas habilidades dos docentes, sem considerar o engajamento destes, a necessidade das tecnologias e sem trazer para os currículos conceitos que unificassem seus usos específicos. Observaram ainda que essa abordagem funcionalista traz implicações para o envolvimento acadêmico, o currículo e os perfis dos docentes. A partir dessa problemática, eles reinterpretaram o modelo dos quatro recursos do letramento crítico, criado por Peter Freebody e Alan Luke (FREEBODY; LUKE, 1990), em uma perspectiva digital e o adaptaram para docentes de graduação e pós-graduação. Essa construção também teve como objetivo desenvolver experiências e aplicações curriculares, de forma a apoiar e avaliar o desenvolvimento do letramento digital em contextos práticos. Por essa razão, decidimos aprofundar o seu uso nesta pesquisa.

\section{O Modelo dos Cinco Recursos do Letramento Digital Crítico}

Segundo Hinrichsen e Coombs (2013), o modelo dos quatro recursos do letramento crítico é adotado internacionalmente e é usado por ser uma estrutura que permite analisar objetivamente o desenvolvimento curricular, de sala de aula e da cognição docente. Para um letramento bem-sucedido, o leitor deve se envolver nos quatro recursos ou papéis do leitor, os quais são interdependentes: (1) a decodificação (code breaker) diz respeito a decifrar e produzir textos e inclui um entendimento de gramática, funções e aspectos estruturais; (2) a produção de significados (text-participant ou meaning maker) se relaciona às interpretações e relações construídas a partir do texto; (3) a utilização (text user) se associa ao uso do texto no tempo e espaço presente; e, (4) a análise (text analyst) envolve compreender quais são os interesses do texto, ou seja, o que está além do que é apresentado.

O modelo dos quatro recursos focaliza os papéis do leitor e o contexto digital caracteriza-se também pela autoria. Por isso, Hinrichsen e Coombs (2013) criaram o quinto recurso: imagens pessoais (persona), considerando a criação, modelagem, adaptação e cocriação de textos. Os cinco recursos do letramento digital crítico estão relacionados à 
prática e a um conjunto de habilidades a serem desenvolvidas e aprimoradas, as quais se inter-relacionam e se sobrepõem. São "famílias de prática", o que significa que não detalham competências específicas, mas áreas de interpretação e gestão do professor. Elas são: decodificação (decoding), produção de significados (meaning making), usos (using), análise (analysing) e imagens pessoais (persona), conforme a tradução do modelo original.

O recurso decodificação envolve a habilidade de decifrar e produzir textos digitais a um nível prático. Inclui um entendimento da gramática e das funções e estruturas desses tipos de textos. Segundo os autores, "[...] os docentes precisam desenvolver familiaridade com as estruturas e convenções dos meios digitais, sensibilidade aos diferentes modos de funcionamento dos artefatos digitais e o uso confiante das estruturas operacionais". (HINRICHSEN; COOMBS, 2013, p. 8, tradução nossa).

A produção de significados propõe incentivar processos reflexivos que sustentam a compreensão e a composição dos textos, estabelecendo um diálogo com a experiência e o conhecimento prévio do leitor. Os propósitos e convenções dos textos podem estar sujeitos a mudanças ou fragmentação, tornando as práticas de leitura e criação também fluidas. Os autores consideram que os "textos de rede" são compostos por outros textos e, por isso, são necessários múltiplos níveis simultâneos para criação de significados.

O recurso usos se refere à utilização de textos específicos para determinadas finalidades e envolve a compreensão das características particulares dos diferentes textos e das necessidades específicas de seus contextos de utilização.

A concepção, produção e divulgação dos textos requer um repertório de competências e avaliação crítica das escolhas e implicações. Além disso, a escala informacional da internet e de bancos e conjuntos de dados especializados exigem habilidades de busca, localização e formulação de consultas, além de resolver os problemas práticos que surgem ao utilizar as tecnologias digitais. Quando a autoria é mediada digitalmente, as questões de procedência tornam-se complexas. A avaliação crítica é fundamental nesses contextos e pode servir inicialmente para rastrear a proveniência e discernir a ideologia da fonte do texto. Estas habilidades estão relacionadas ao recurso análise e uma preocupação é a tomada de decisões legais, éticas e morais sobre como, onde e para quem publicar. A multiplicidade de caminhos para a publicidade e os canais de comunicação variados e globalizados requerem escolha e julgamento sobre como, onde e quando participar e para quais fins.

Um dos desafios reside na apresentação do eu e o recurso imagens pessoais, em suas origens, considera a participação mediada por formas textuais multimodais e também a reputação, projeção de imagens e relações interpessoais mediadas pelas tecnologias. $O$ desenvolvimento e o gerenciamento da personalidade on-line podem ser considerados como um atributo profissional e são efetivamente desenvolvidos em conjunto com outros recursos de letramento. Em imagens pessoais (persona), a orientação é desenvolver: "[...] sensibilidade às questões de reputação, identidade e filiação dentro de diferentes contextos digitais. A gestão proposital e ajuste de uma pessoa que está on-line. A progressão do sentimento de pertencer e ter confiança na participação" (HINRICHSEN; COOMBS, 2013, p. 12, tradução nossa). 
Figura 1 - O modelo dos cinco recursos do letramento digital crítico

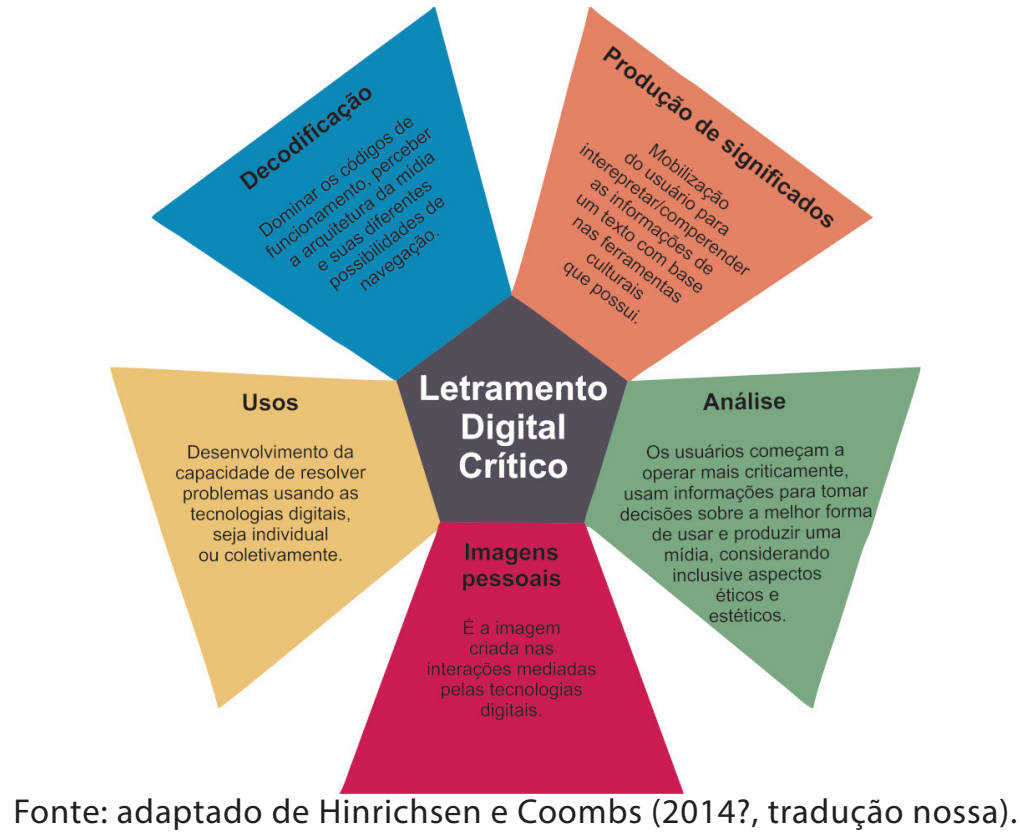

\section{Metodologia}

A pesquisa realizada apresenta características de uma pesquisa-intervenção, uma vez que ocorreu junto à proposição de uma experiência de formação docente com introdução de um 'novo' conteúdo, abordagem e inovação no currículo do curso de licenciatura envolvido. Esse tipo de intervenção é tipicamente caracterizado pela realização de uma avaliação diagnóstica para analisar o público alvo quanto às suas dificuldades, seguida do desenvolvimento de uma intervenção utilizando técnicas de ensino, artefatos ou produtos didáticos que inovem e provoquem reflexão dos participantes com avaliação final dos resultados (MACIEL; PASSOS; ARRUDA, 2018).

A questão de pesquisa definida foi: quais são os efeitos do modelo dos cinco recursos e que outros aspectos emergem da prática formativa proposta para o letramento digital crítico dos licenciandos? A experiência foi desenvolvida no âmbito de uma unidade curricular obrigatória de um curso de Licenciatura em Química, na Universidade Federal de São João del-Rei, a qual é oferecida no último período do curso e cuja ementa propõe aproximar os licenciandos da pesquisa na área do ensino de ciências e de química, analisar e desenvolver metodologias de pesquisa, registrar dados e analisar pesquisas desenvolvidas.

Assim, a introdução à pesquisa em ensino de ciências e química foi estabelecida inicialmente por uma apresentação oral dialogada com apoio de slides em Powerpoint tratando de seu surgimento relativamente recente, seus objetos de estudo, justificativas, relações com o ensino e relevância para a formação docente. Depois, foram discutidas as concepções de Stenhouse e Schön sobre o "professor-pesquisador" e "reflexivo", o surgimento da "pesquisa-ação", da pesquisa sobre a prática docente e da formação de pesquisadores em ensino de ciências. Apesar da variedade de referências para aprofundar esses assuntos, os trabalhos foram guiados pelos textos de Fagundes (2016), Oliveira e Gonzaga (2012), Schnetzler (2002, 2004), e Schnetzler e Aragão (2015). 
Após essa discussão, cada licenciando leu dois resumos de trabalhos publicados em eventos científicos, sendo um regional e outro nacional, e depois um artigo extraído de um dos seguintes periódicos: Ciência \& Educação, Ensaio: pesquisa em educação em ciências, Investigações em Ensino de Ciências, Revista Brasileira de Pesquisa em Educação em Ciências e Química Nova na Escola (seção Pesquisa em Ensino). Primeiramente foram apresentados os periódicos e depois fornecidos os seus endereços eletrônicos para que os licenciandos acessassem e selecionassem um artigo livremente para leitura e apresentação. A única condição foi que o artigo tivesse relação com uma pesquisa em ensino de química. Entre cada uma das leituras propostas, foram focalizadas as questões de pesquisa, as metodologias e os resultados. Alguns exemplos de dissertações e teses também foram apresentados a eles.

Posteriormente, os licenciandos foram introduzidos à presente pesquisa, conforme descrito mais adiante e, depois, desenvolveram as suas próprias. Durante cinco semanas trabalharam em grupos na investigação de temas escolhidos por eles, sob a orientação da pesquisadora e do docente da disciplina (autores do presente texto), tendo por base o referencial teórico do modelo dos cinco recursos do letramento digital crítico. As seguintes etapas foram definidas para a realização de suas pesquisas: formulação de uma pergunta, definição do objeto de estudo e dos procedimentos metodológicos, coleta e análise dos dados e apresentação oral dos resultados. Os resumos das pesquisas realizadas foram socializados posteriormente no Portal Didático da disciplina.

Cada grupo deu um direcionamento e escolheu um tema diferente para investigar o modelo, sendo eles: (1) As apresentações acadêmicas utilizando o Power Point: uma aprendizagem traumática para os alunos de graduação em Química?; (2) O uso do celular entre professores e alunos do curso de Química da Universidade Federal de São João del-Rei; (3) A utilização de recursos digitais nas aulas de química do Instituto Auxiliadora, uma escola privada do município; (4) A construção de modelos químicos concretos ainda é necessária na era digital em que vivemos?; e, (5) Análise das postagens sobre a química do cotidiano na página do curso no Facebook com base no modelo do letramento digital crítico.

$\mathrm{Na}$ introdução dos licenciandos em nossa pesquisa, inicialmente explicamos que estava sendo desenvolvida uma investigação no âmbito de uma dissertação de mestrado em educação e os convidamos a participar. Foi dito que se tratava de uma pesquisa sobre letramento digital e que a participação deles proporcionaria uma vivência de pesquisa e traria aprendizagens. Não houve nenhuma recusa à participação. Assim, descrevemos as etapas do processo e solicitamos que preenchessem um questionário visando conhecer suas relações com as tecnologias digitais. Foram elaboradas 16 perguntas e algumas se basearam nas habilidades previstas no modelo teórico adotado. As questões contemplaram: os dispositivos e recursos utilizados e a intensidade de uso de cada um; a frequência diária do mais usado; a finalidade e facilidade dos usos; a experiência com esses recursos em salas de aula; as facilidades e estratégias para interpretar e entender as informações acessadas; como avaliavam suas capacidades para resolver problemas nesses ambientes e para julgarem e selecionarem o que produziam ou usavam; se havia identificação com os espaços digitais e se sabiam o que é letramento digital.

A partir dos dados do questionário e da maior ou menor familiarização com o uso das tecnologias digitais, decidimos compor dois grupos de licenciandos para observação com registro audiovisual: um com aqueles que os dados do questionário sugeriram ser mais letrados digitalmente e outro com os menos letrados, cada qual com quatro integrantes. Como hipóteses, consideramos que essa composição dos grupos influenciaria a forma como 
interagiriam com as mídias pré-selecionadas e que a prática formativa teria efeitos distintos de acordo com a heterogeneidade da turma. Desse modo, poderíamos observar um grupo com tendência a ter maior facilidade com as habilidades apontadas pelo modelo e perceber as dificuldades do outro.

Os dois grupos foram direcionados para duas pequenas salas adjacentes à sala onde ocorreram as aulas da disciplina, nas quais havia dois computadores. A fim de registrar suas ações, foi posicionada uma filmadora atrás de cada grupo, possibilitando vê-los de costas com foco na tela do computador. Os outros três grupos ficaram na sala de aula, cada qual em um computador. O portal didático e o aplicativo WhatsApp foram utilizados para compartilhar textos, slides e informações.

As mídias selecionadas para análise dos licenciandos foram o DVD e a hipermídia $O$ doce de leite, as quais foram produzidas em um projeto anterior financiado pelo Programa de Extensão Universitária (ProExt) apoiado pela Secretaria de Educação Superior (SeSu) do Ministério da Educação (MEC). Além de trabalharem conteúdos de química, essas mídias foram selecionadas por serem multimodais ou apresentarem recursos variados integrados, tais como áudios, vídeos, textos, tabelas, animações, imagens e fotografias. Uma hipermídia configura um sistema informacional e comunicacional que associa imagens (reais ou animadas), sons e textos escritos em um único suporte, usando a internet ou uma mídia para leitura óptica no computador (MELEIRO; GIORDAN, 1999). Em seu aspecto informacional, é um instrumento que veicula informações; em seu aspecto comunicacional, na concepção da hipermídia sobre o doce de leite foram inseridos elementos para promoção de diálogos entre os estudantes e destes com outras mídias para a produção de significados, como a inserção de botões animados que revelavam perguntas para interpretação do conteúdo, por exemplo.

Conforme apresenta em seu início, o DVD "[...] expressa saberes e práticas relativas ao preparo do doce de leite, conforme a cultura popular", e mostra cenas de saberes e práticas de três pessoas da comunidade local. A hipermídia associa-se ao DVD e aprofunda os saberes, acrescentando o conhecimento científico a uma narrativa escrita-áudio-visual que focaliza os saberes específicos de Dona Mariinha sobre o preparo do doce de leite.

A primeira interação com essas mídias ocorreu sem direcionamentos, ou seja, os grupos as exploraram de modo autônomo. Cada integrante recebeu uma cópia do DVD e da hipermídia. Inicialmente, a classe foi orientada a explorar os materiais como desejasse. Alguns optaram por acessar o DVD primeiro, outros a hipermídia. Após essa exploração inicial, ocorreu uma discussão coletiva sobre a experiência com todos os grupos. Na aula seguinte, foi feita a intervenção sobre o modelo dos cinco recursos do letramento digital crítico, por meio de uma exposição oral dialogada com o apoio de slides em PowerPoint, cuja duração total foi de 40 minutos. Para introduzir as discussões, primeiramente assistimos ao vídeo Evolução das tecnologias na educação (2016). Depois, foram apresentados os conceitos de letramento, letramento digital e o modelo dos cinco recursos: como foi criado, a razão de sua criação e seus componentes.

Na segunda interação dos licenciandos com as mídias, disponibilizamos a apresentação do modelo em PowerPoint e PDF para cada grupo nos computadores, bem como uma folha contendo um resumo impresso das categorias do modelo, e os integrantes desses grupos seguiram revendo suas interações iniciais com as mídias e analisando e discutindo os constituintes do modelo. Nesta etapa, ao mesmo tempo em que agiram na direção de 
compreenderem o modelo, eles interagiram novamente com o DVD e a hipermídia, avaliando como os exploraram antes de conhecerem o modelo e o que este lhes sugeria fazer. Os grupos criaram tabelas de comparação entre as características dos recursos do modelo e o que desenvolveram. Após isso, ocorreu outra discussão coletiva mediada pelos relatos dos grupos.

As duas explorações das mídias pelos integrantes dos grupos duraram cerca de duas horas. Após essas, ocorreram as discussões com toda a turma, as quais foram realizadas em cerca de uma (primeira discussão) e duas horas (segunda). Nestas discussões e na apresentação do modelo, duas filmadoras foram posicionadas na sala, uma na frente e outra atrás da turma, e foi utilizado um caderno para as anotações relativas aos acontecimentos.

Para realizar a análise, inicialmente averiguamos os dados obtidos durante a pesquisa. Havia os questionários respondidos pelos licenciandos e $10 \mathrm{~h} 4 \mathrm{~min} 36 \mathrm{~s}$ de gravação em vídeo. Esse registro foi transcrito de acordo com: $3 \mathrm{~h} 13 \mathrm{~min} 26 \mathrm{~s}$ da primeira interação com o DVD e a hipermídia (grupos 1 e 2), 1h03min37s da primeira discussão plenária com a turma, 4h00min54s da segunda interação com as mídias (após a apresentação do modelo) e 1 h47min12s da segunda discussão em plenária. Com o objetivo de analisar os efeitos do modelo e a experiência formativa para o letramento digital crítico dos licenciandos, realizamos a análise de conteúdo proposta por Bardin (1994). Para realizar esta análise, revimos as anotações, assistimos aos vídeos, realizamos suas transcrições e selecionamos falas representativas.

De acordo com a pergunta da pesquisa, procuramos observar os efeitos do modelo dos cinco recursos do letramento digital crítico nos licenciandos. Devido a isso, foram definidas cinco categorias a priori, cada qual correspondente aos cinco recursos. Porém, como também atentamos aos aspectos que emergiram da prática formativa desenvolvida, as unidades de significados (falas dos licenciandos) foram organizadas em 13 subcategorias do seguinte modo:

Quadro 1 - categorias e subcategorias de acordo com o modelo de cinco recursos do letramento digital crítico

\begin{tabular}{|l|l|}
\hline \multicolumn{1}{|c|}{ Categoria } & \multicolumn{1}{c|}{ Subcategoria } \\
\hline Decodificação & - Percepção operacional e estrutural; \\
& - Percepção espacial; \\
& - Percepção e diferenciação dos elementos; \\
& - Navegação íntegra. \\
\hline Produção de significados & - Saber popular e científico; \\
& - Conhecimento prévio; \\
& - Leitura. \\
\hline Usos & - Aplicação do material digital; \\
& - Resolução de problemas; \\
& - Abordagens criativas. \\
\hline Análise & - Crítica \\
\hline Imagens pessoais & - Percepção do conhecimento e gosto próprio; \\
& - Relação com os participantes. \\
\hline
\end{tabular}

Fonte: elaborado pelos autores.

Para preservar a identidade, cada licenciando recebeu um código conforme a lista de presença. O primeiro da lista recebeu o código A 1 e assim por diante. Os grupos 1 e 2 se referem àqueles com maior e menor familiaridade ou facilidade de interação com as tecnologias 
digitais, respectivamente. Também foi criado um código para cada momento no qual as falas foram expressas. Assim, a primeira interação com as mídias e a discussão posterior receberam os códigos i1 e d1, e a segunda interação com as mídias e a discussão seguinte foram codificadas por i2 e d2, respectivamente. Denominamos por interação o conjunto de ações dos licenciandos com as mídias (o que fizeram e falaram) e por discussão as trocas coletivas com toda a classe, nas quais surgiram dúvidas, questionamentos, comentários e observações relativas às interações. Após essa experiência, os licenciandos desenvolveram suas pesquisas na comunidade acadêmica e escolar local conforme mencionado anteriormente.

\section{Resultados e Discussão}

Apresentamos, a seguir, os resultados da pesquisa segundo os cinco recursos do letramento digital crítico e suas respectivas subcategorias identificadas nas falas dos licenciandos.

\section{Decodificação}

A subcategoria percepção operacional e estrutural considera as operações comuns em ambientes digitais e a confiança no uso de suas ferramentas e aplicações, além das normas e convenções. Os participantes do grupo 1 creditaram a capacidade de lidar com as mídias digitais à já terem explorado outras hipermídias em uma disciplina cursada anteriormente: "[...] o manuseio mesmo da hipermídia, a gente conseguiu fazer sem dificuldade nenhuma, porque a gente tinha feito isso também na disciplina de PRAE III. Todo mundo do grupo já tinha feito. Então, essa parte foi super tranquila" (A8d2). O acréscimo dado pelo conhecimento do modelo foi a organização que ofereceu: "A gente já tinha conhecimento disperso. A gente viu o modelo, a gente conseguiu organizar e sistematizar esse conhecimento na nossa cabeça. A gente já tinha tido contato, mas ele ajudou a organizar" (A8d2).

Apesar de não ter demonstrado grandes problemas de navegação, o grupo 2 teve algumas dificuldades, como foi o caso, por exemplo, do acesso a uma página onde havia uma fotografia que não agia como botão de comando: "Volta. Sair. Cê clicou nela, por isso que foi aî" (A15i1), "Não cliquei nela" (A10i1), "Foi direto" (A13i1), "Será gente?" (A15i1). Assim, percebemos esse indicativo de falta de "[...] confiança no envolvimento com novas ferramentas ou aplicações" (HINRICHSEN; COOMBS, 2013, p. 8, tradução nossa) por parte do grupo menos familiarizado com os ambientes digitais, sinalizando a necessidade de atenção na formação para o letramento digital.

A percepção espacial refere-se ao domínio da espacialidade ou arquitetura dos ambientes digitais para não se perder durante a exploração. O que "[...] implica ser capaz de localizar-se espacialmente", segundo Hinrichsen e Coombs (2013, p. 8, tradução nossa). Considera a identificação de um sistema de navegação contínuo, sem interrupções por falta de localização. A não obrigatoriedade de seguir uma ordem de exploração foi uma questão abordada na primeira discussão com a classe. Uma licencianda relatou: "Só que aí você está em determinado tópico. Aí você vai clicando naquilo, vai entrando, quando você assusta, cê tá assim: por que quê eu tô? O que eu tava lendo antes?", e complementou dizendo que isso teve relação com a quantidade de conteúdos: "Às vezes, por isso que a gente não conseguiu traçar essa linha de raciocínio do processo como um todo. Muita informação" (A5d1). Essa fala revela uma dificuldade em seguir as informações na hipermídia, de modo a traçar uma linha de continuidade. 
Para não se perder, o grupo 1 optou por guiar-se pela sequência de informações apresentada nas mídias e definida em seus menus. A mesma licencianda explicou em outro momento: "Eu sei que a exploração é livre. Mas assim, pelo menos quem tem, eu sou sempre convencional, pelo menos a minha tendência é sempre ficar no primeiro tópico e como tinha opção de próximo, eu ia no próximo" (A5d2).

O grupo 2 descreveu uma navegação mais aleatória, possivelmente devido à menor familiarização com as novas tecnologias. Por isso, seus participantes tiveram problemas de localização, conforme mencionaram após conhecerem o modelo: "Olha esse aqui [se referindo ao recurso decodificação]. A gente pecou. A gente se perdeu no meio da navegação. Conhecendo esse negócio aqui, [o modelo] a gente pode falar que a gente prestaria mais atenção aonde cada aba leva a gente, aonde cada hiperlink leva a gente" (A13i2).

Outro licenciando relatou posteriormente: "A gente encontrou muita dificuldade de saber da ordem sequencial, se ia pra frente, pra trás. A gente nem prestou atenção nisso. Tanto é que a gente começou a olhar a hipermídia de trás pra frente. A gente não tava entendendo nada. Aí que a gente foi olhar que a gente tava indo de trás pra frente. A gente começou lá no final. Então, agora a gente ia fazer assim, uma análise melhor, né. la prestar atenção nos ícones" $(\mathrm{A} 17 \mathrm{~d} 2)$.

Essas falas mostram que o modelo sugeriu a A13 e A17 se orientarem pelos elementos de navegação da hipermídia, enquanto que A5 preferiu seguir uma linha de raciocínio. Em sua constituição, a hipermídia busca conciliar esses dois elementos: o encadeamento de informações com a navegabilidade, e perceber isso implica identificar qual é essa lógica. Contudo, as duas últimas falas evidenciam um apoio do modelo e da prática ao desenvolvimento dos menos letrados digitalmente.

A percepção e diferenciação dos elementos diz respeito à percepção dos diferentes elementos digitais, tais como cores, áudio, tipos de letra, layout, botões e links, entre outros, que caracterizam as multimodalidades das mídias digitais. Alguns elementos foram notados e verbalizados pelos licenciandos: "Música animadinha" (A11i1); "Muito didático" [fazendo referência a uma animação] (A14d1), e os hiperlinks foram os mais comentados: "Dá para clicar em cada um desses trem aí. Se você clicar em cada um ali vai dar para ver o que cada um está fazendo" (A13i1); "Esse recurso de hipermídia que cê pode clicar numa palavra e ver o que que ela significa, é muito legal, é muito legal. Achei super bacana o jeito que eles colocaram. Tipo substância, aí cê clicava em substância e aparecia a substância que eles estavam falando, sabe? Até de maneira estrutural mesmo. Desenhando a estrutura. Achei super didático" (A8i1).

Um parecer sobre a relação desses elementos com a linguagem foi a seguinte: "[...] ela [a hipermídia] conseguiu utilizar diferentes formas de expressão que facilitou, que foi a linguagem um pouco coloquial, às vezes imagens, vídeos, até mesmo algumas demonstrações químicas que eles colocaram, que iam mudando. Isso facilitou nossa leitura" (A11d2). Todavia, alguns elementos e detalhes passaram despercebidos: "A gente nem sabia que tinha [se referindo a um dos botões de interatividade da hipermídia]. E aí que a gente foi ver de novo o que tinha e acho que tinha outras coisas também" (A15d2).

Porém, com o modelo, passaram a observar esses elementos: "Foi isso que a gente pensou. Tipo que a hipermídia, ela é composta por diferentes elementos, ferramentas, vídeos. $O$ modelo permitiu a gente fazer uma análise crítica nesse sentido, porque quando a gente analisa a gente vê como um todo" ( $\mathrm{A} 5 \mathrm{~d} 2)$. Assim, houve melhor percepção dos elementos relativos 
"[...] à compreensão das diferentes características e convenções dos modos de textos digitais" (HINRICHSEN; COOMBS, 2013, p. 8, tradução nossa), destacando-se as "[...] diferentes formas de expressão" e "[...] a linguagem um pouco coloquial" das mídias (falas dos produtores do doce de leite).

A navegação íntegra implica fluidez na exploração integral do conteúdo das mídias. Os licenciandos dedicaram mais tempo aos vídeos do que à hipermídia. A justificativa foi: "A gente leu a hipermídia toda, do mesmo jeito que a gente viu os vídeos todos. E demorou menos tempo ler tudo do que assistir" (A8d1). Eles assistiram todas as cenas do vídeo-DVD e, apesar do argumento de que ler é mais rápido do que assistir, percebemos que eles não acessaram todos os componentes da hipermídia. Pensamos que o tempo foi curto, mas, ao assistirmos às gravações, notamos que foi suficiente. Uma licencianda chegou a sugerir: "Vamos aproveitar que a gente viu tudo, volta lá no... Sai daí. Sai. Vai lá na hipermídia do polvilho azedo [disponível no mesmo CD-ROM]. Vamos ver o que que isso" (A14i1). No grupo 1: "A gente vai colocar a hipermídia?" (A8i1), "Vocês que sabem pra gente não ficar à toa, né?" (A7i1), e no grupo 2: "Colocar o videozinho [o DVD] e deixar rolando" (A13i1), "Deixa rolar" (A10i1).

Um deles disse que, na primeira interação com as mídias, o grupo estava apenas as conhecendo: "Nós tivemos uma visão mais geral, mais superficial a respeito da hipermídia. Nós não buscamos aprofundar muito o conhecimento. Só passamos pra conhecer ela mesmo, então nossa navegação foi voltada nisso" (A6d2). Na segunda interação, observamos uma diferença na qualidade da navegação nos dois grupos, seja por terem compreendido melhor a finalidade dos trabalhos, por terem conhecido o modelo e/ou por já estarem familiarizados com a hipermídia. Um licenciando disse: "Em questão de conseguir explorar mais, de maior confiança, a gente sentiu uma diferença" (A15d2); "Foi uma interação muito superficial. Eu acho que após conhecer o modelo a gente teria interagido de uma forma mais completa, teria lido com mais atenção os conteúdos, as coisas assim" (A21d2).

Esses dados mostram que, para alguns, o modelo chamou atenção para a integridade da navegação, uma vez que essa "[...] relaciona-se à compreensão dos mecanismos de navegação [...] e noções de movimento na paisagem digital, tanto conceituais [....] quanto práticas" (HINRICHSEN; COOMBS, 2013, p. 8, tradução nossa).

\section{Produção de significados}

O saber popular e o científico foram os dois saberes veiculados pelas mídias e essa subcategoria associa-se às relações de significação que os licenciandos estabeleceram com eles. O primeiro diz respeito ao conhecimento da comunidade local sobre o doce de leite e o segundo à interpretação química dos processos ocorridos na produção do doce. Observamos que houve maior atenção pelo saber popular e questionamos os licenciandos a esse respeito. E assim, cada um/a expressou seu "[...] propósito, intenção, sentimento ou ideia" (HINRICHSEN; COOMBS, 2013, p. 9, tradução nossa).

Alguns se justificaram do seguinte modo: "Eu realmente fiquei muito fascinada pelo vídeo, porque eu nunca vi fazendo um doce de leite na minha vida. [...] Quando foi pra olhar a química, eu li a química, falei: 'Ah bacana, mas o doce de leite, olha que legal!'. Me chamou mais atenção mesmo, porque eu nunca tinha visto" (A8d1). Outro licenciando disse: "Ah, eu acho que foi isso que aconteceu no nosso grupo. Eu também nunca tinha tido contato com a fabricação do doce de leite. Então, a parte química, pelo menos do nosso grupo a gente foi passando, falando 
assim: 'ah então é isso?', não se apegou naquilo. Leu mais superficialmente: 'Ah realmente tem explicação', mas não se apegou naquilo pra ligar os dois processos. [...] A gente achou interessante ter uma explicação científica para o que elas estavam fazendo, mas foi muito superficial [a exploração]" (A5d1).

Essa discussão prosseguiu na segunda interação dos grupos com as mídias: "A gente faria diferente? Faria, né. Eu acho que a gente tinha que dar o enfoque maior no saber científico nesta parte" (A11i2); "Na verdade, eu acho que é pegar o conteúdo que a gente viu lá e relacionou com o que a gente conhecia ou que a gente achava que conhecia, entendeu? A gente não fez isso de uma maneira, por exemplo, a gente sabia lá que o leite ferve, quê que acontece com a nata, mas a gente não levou para o conhecimento químico mesmo. A gente não teve curiosidade direito de saber o que acontece" (A13i2).

Na discussão coletiva após a segunda interação com as mídias, um licenciando reforçou que o recurso produção de significados sugeria dar atenção também para os conteúdos de química da hipermídia: "No início, a gente só relacionava com nosso dia a dia. Por exemplo, a A2 falava como ela fazia, a mãe dela fazia. A gente foi relacionando com o nosso cotidiano e após o recurso a gente ia buscar pro lado químico mesmo" (A19d2).

Alguns falaram que a falta de direcionamento inicial fez com que dessem maior atenção ao saber popular por ser "mais fácil": "Já que era pra ver o vídeo sem... livre, a gente não tinha objetivo específico. A gente foi ver o que era mais fácil, assim, o que era mais comum" (A8d1).

Essas falas mostram que as mídias cumpriram a função de transportar os saberes da comunidade para uma sala de aula e, ao mesmo tempo, evidenciaram a necessidade de direcionar a exploração para o conhecimento químico explicativo. As próprias mídias direcionaram a atenção, conforme mencionou um licenciando: "Acho interessante, porque primeiro vem uma parte falando sobre a explicação popular e depois o científico. Então cê já fica, parece que já te induz a ir primeiro no popular pra você se certificar de tudo o que você viu no vídeo, para depois você relacionar com o científico" (A5d1).

Assim, as mídias mostraram ter cumprido um papel importante na formação dos licenciandos, ao aprofundarem seus conhecimentos advindos da cultura primária e também da formação escolar. No caso, o modelo contribuiu mais no sentido de chamar atenção para essa última (por ter sido menos explorada inicialmente). Houve também quem tenha atribuído a maior atenção pelo saber popular ao cansaço, tendo em vista a quantidade de informações: "É, porque a gente ficou muito tempo no saber popular. E aí a gente foi pro científico, claro, a gente achou legal, mas a gente tava mais cansada mesmo. Se a gente tivesse vendo um e outro o mesmo tempo. Acho que teria sido mais interessante a exploração" (A8d2).

O conhecimento prévio considera o que os licenciandos já sabem como determinante inicial dos processos de significação do conteúdo digital, relacionando o conhecimento novo ao antigo. O letramento digital busca "[...] estreitar as relações entre o conhecimento novo e o existente e desenvolver e adaptar modelos mentais". (HINRICHSEN; COOMBS, 2013, p. 9, tradução nossa). Os licenciandos mencionaram que as suas experiências anteriores fizeram com que interagissem mais com o saber popular: "[...] Três participantes do grupo, eles tinham esse diálogo com o conhecimento das famílias sabe, hereditário deles. Então, querendo ou não, nossa discussão ficou muito voltada para isso" (A5d2).

O conhecimento prévio foi algo muito recorrente na exploração, principalmente para aqueles que tinham em casa pai, mãe, avó ou avô que faziam doce de leite. Uma licencianda chegou a pesquisar o processo com sua avó e trouxe fotos desse momento. 
Outra contou: "Meu pai não aceita fazer no fogão a gás não. Ele gosta de fazer no fogão de lenha" (A11i1). Outros destacaram suas vivências com o assunto e compararam os saberes: "Gente! Nossa! Melhor coisa da vida. Lembrança da minha infância é sentar no rabo do fogão assim, e raspar esse tacho. Quente ainda" (A14i1); "Esse a gente fez muito bem. Toda hora a gente ficava lembrando de alguma coisa. A gente conseguiu bem linkar nossa vida com o que a gente tava vendo" (A8i2); "É igual o pires. Minha vó também usa o pires, e aí eu comentei com ela: 'Mas pra que o pires?' Ela falou assim: 'É para não entornar o leite.' Mas ela não sabe o que ele faz lá dentro que não entorna o leite" (A9d1).

Pode-se dizer que a análise do recurso produção de significados levou-os a perceber o papel desempenhado pelo conhecimento prévio e os dados apresentados acima evidenciaram que este também foi um determinante da maior atenção conferida aos saberes da comunidade nas mídias.

Por leitura atribui-se fluidez e confiança nas interações com o código escrito dos conteúdos digitais. Nos dois grupos observados, os licenciandos leram silenciosamente os textos da hipermídia e somente um deles o fez em voz alta. Mas eles não leram todo o conteúdo. Uma licencianda falou para os integrantes de seu grupo: "A gente não precisa ler tudo" (A11i1).

Já na segunda interação com a hipermídia, os licenciandos começaram a caracterizar o tipo de leitura realizado: "Mas a leitura foi fluindo. Só que tipo não é aquela leitura que a gente fala que é uma leitura de aprendizado, sabe, uma leitura que a gente fica bem mesmo superficial" (A22d2). Alguns disseram que, após a apresentação do modelo, houve algumas mudanças: "[...] Depois do modelo, a gente achou que foi mais fácil, foi melhor. Acho que talvez por causa do direcionamento" (A15i2); "A gente achou que houve um aumento de interesse da nossa parte depois que a gente viu o modelo. Em questão de mexer na hipermídia, procurar" (A15d2); "Depois do modelo a gente observaria isso com mais detalhes e, por exemplo, a leitura mesmo geral, como a gente poderia fazer de uma outra forma" (A19d2). Essas falas demonstram que os licenciandos leram o conteúdo sem compreendê-lo completamente, conforme: "leitura leve", "superficial", "sem preocupação de aprendizado".

Por isso, fazer uma exploração inicial livre, sem direcionamento, foi interessante para constatar como foram suas leituras espontâneas com as mídias e o que o modelo lhes sugeria fazer. Esse os auxiliou a perceber o tipo de leitura que fizeram e, em relação aos conteúdos não acessados, ofereceu uma direção, pois a leitura na produção de significados é a capacidade de seguir e criar uma narrativa, utilizando vários elementos semânticos, visuais e estruturais. (HINRICHSEN; COOMBS, 2013).

\section{Usos}

A aplicação do material digital revela as sugestões que os licenciandos deram para o uso educacional das mídias, considerando como utilizar o DVD e a hipermídia sobre $O$ doce de leite em salas de aula da educação básica. Como isso não ocorreu espontaneamente nos grupos, levamos o assunto para a primeira discussão, perguntando-lhes a respeito. Uma licencianda respondeu inicialmente dizendo: "Pensei: ele está com letras grandes. Ele tá colorido. Na hora que eu vi aquela entradinha com os lápis de colorir [referente ao menu do DVD], eu, Ah que bonitinho. Tá muito cara de... pros meninos verem', sabe? Eu vi meus alunos abrindo ali, gostando." (A10d1). 
Porém, a maioria revelou que não refletiu sobre a utilização didática das mídias. Uma licencianda justificou isso associando à liberdade que demos para a interação: "Se eu recebesse aquele material como professora, sabendo que era um material pra eu aplicar em sala de aula, eu teria olhado com outros olhos pro material"(A8d1). Também disseram que foi porque não entenderam que deviam pensar assim: "Em questão de exploração mesmo. A gente usou adequadamente. A gente explorou adequadamente. A gente não pensou que era para falar como usaria, tipo..." (A8d2).

Essas falas levaram a refletir com os licenciandos sobre a consciência de quem eram e onde estavam: licenciandos cursando uma disciplina de formação específica de um curso de licenciatura e, após se insistir na questão, as sugestões afloraram em maior número:

- "Eu dividiria o tempo. Pegaria uma metade do conhecimento popular e a outra metade do conhecimento científico. la ficar alguns minutos só no conhecimento e na outra aula, eu daria a matéria" (A6d1);

- "Eu acho que, pensando em ensino médio, eu acho que eu começaria perguntando eles, por exemplo, se eles acham que tem química no doce" (A18d1);

- "Em outra aula eu ia trazer a hipermídia pros meninos olharem e mexerem e ia explicar o conteúdo químico. E aí, mas assim, tudo isso com umas duas aulas introdutórias pra um assunto que já tem ligação, sabe, assim, que já tem algum conteúdo do livro didático deles mesmo. Depois ia começar explicar sobre... Não sei... Não sei o que um discente do ensino médio estuda disso. Eu teria que pegar o vídeo e pesquisar e ol har qual o conteúdo que eu poderia interligar" (A8d1);

- "Perguntaria se aquilo que é aquele processo. Depois eu explicaria o conteúdo e levaria com a hipermídia pra eles saberem o conteúdo que eu tinha explicado com o vídeo de introdução tinha nexo" (A7d1);

- "Eu deixaria eles olhando livremente, durante uns 20 a 30 minutos, depois começaria dando funções orgânicas ou mecanismo de reação, algo assim, se fosse o caso. Mecanismo não tem muito no ensino médio, né?" (A10d1).

Algumas falas chamaram a atenção por revelarem a necessidade de interligar conteúdos, sejam referentes ao livro didático ou ao currículo escolar, conforme mencionado por A8. A fala de A6 mostrou a influência do formato das mídias em sua proposta para salas de aula, pois a hipermídia com a qual interagiu foi organizada em duas partes: os saberes da comunidade de um lado e os da ciência de outro. Alguns comentaram que não aplicariam todo o material ou não o utilizariam ou fariam isso em pouco tempo, indicando darem maior importância aos conteúdos tradicionalmente ensinados ou determinados pelos currículos e livros didáticos de química, como sugeriram A8 e A10. Essas posturas nos sugeriram haver dificuldades de associar o ensino de química aos saberes sobre o doce de leite, e usar as mídias para isso, o que pode ter relação com uma visão universalista de ciência, uma vez que os saberes teriam que ser relacionados aos conteúdos da química escolar e o tempo não poderia comprometer o programa curricular ("ia ficar alguns minutos"; "durante uns 20 a 30 minutos").

Apesar disso, alguns licenciand os também consideraram fatores como a disponibilidade de recursos na escola: "mas aí depende da escola que cê tá trabalhando também. Porque pode ser que os docentes não têm acesso [às tecnologias]" (A10d1), e o papel do professor: "às vezes num primeiro contato mesmo, o docente sozinho, ele pode se interessar pelo popular, mas aí o papel do professor é importante nisso, de trazer a química depois dessa aula de exposição" (A8d1). 
A resolução de problemas aborda as dificuldades durante a interação com as mídias e as possíveis soluções dadas. Na segunda interação e na segunda discussão, eles contaram quais foram os problemas com os quais se depararam, como, por exemplo, quando o computador do grupo 1 não estava funcionando. Eles falaram: "a gente não teve que salvar e imprimir nada. Mas iniciar, desligar" (A11i2) e "a dificuldade foi o computador também que não ajudou, né?" (A6i2); "Não foi culpa nossa. Foi dele" (A7i2). Noutra situação, o problema foi com a hipermídia: "até mesmo tivemos dificuldade de abrir a hipermídia. Tivemos ali que arrumar um jeito pra tentar solucionar o problema. A gente teve bastante confiança em explorar o material e não exploramos nenhuma inovação assim, por ser algo que não tínhamos conhecimento ainda" (A6d2).

Um dos grupos se referiu aos problemas não de forma operacional, mas estrutural: "[...] a gente começou de trás pra frente, a gente não tava entendendo o quê que a gente estava fazendo. A gente tava achando que tava tudo sem sentido. A gente parou, pensou e avaliou qual que seria a melhor sequência para a gente. A gente resolveu a dificuldade que a gente tava" (A19d2). Isto está relacionado ao recurso 'usos', no qual o componente 'resolução de problemas' se refere à capacidade de "[...] explorar ferramentas digitais, recursos e redes para encontrar, definir e analisar os problemas e soluções" (HINRICHSEN; COOMBS, 2013, p. 10, tradução nossa).

Para acessar a hipermídia e o DVD, quando houve dificuldades, estas foram resolvidas com nossa ajuda, o que, de certo modo, referendou a avaliação a respeito das habilidades deles para as questões mais operacionais. Todavia, essas falas expressam problemas de ordem funcional e não aplicadas a um ou mais contextos. Foi nesse momento que se percebeu a falta na prática formativa da problematização de algum conteúdo, como, por exemplo, sugerir que respondessem às questões propostas na hipermídia, ou colocar um problema de ordem educacional do tipo: como explorar as três cenas do vídeo-DVD em uma aula de 50 minutos? Sem esse direcionamento, os problemas identificados pelos licenciandos tiveram relação com o funcionamento do computador e a desorientação na navegação de um dos grupos.

Em abordagens criativas consideramos a criatividade e as ideias dos discentes, principalmente, para aprimorar o DVD e a hipermídia. Nas discussões, eles sugeriram mudanças para ambos. Houve sugestões mais simples, como na composição dos vídeos: "o do Chico [um dos produtores do doce de leite] eu queria que tivesse vídeo, mas só tinha imagem" (A15d1). Uma licencianda propôs inserir um jogo para maior interação: "Sabe o que poderia ter? Um jogo. Iguais àqueles que a gente fez em Natureza da Ciência [outra disciplina]. Porque aí tinha várias tabelas que você relacionava o popular com a fundamentação teórica. Tipo, esse termo significa aqui na teoria. Aí às vezes acho que a gente ia fazer esse tipo de atividade e ia conseguir ir interligando. Eu acho que ia ser interessante. Porque assim, a gente ia trabalhar a mente pra isso" (A5d1).

Outra pensou em uma estratégia de aproximação entre os saberes, com base na experiência que teve com o sítio 'Ciência na Comunidade'1: "de forma geral, todo mundo teve essa dificuldade. Que quase ninguém prestou tanta atenção no conhecimento científico. Acho, que se eu pudesse reformular a hipermídia, eu colocaria conhecimento popular e científico lado

\footnotetext{
${ }^{1}$ Trata-se de uma experiência de formação docente proposta pelo segundo autor desse texto que envolve interação com narrativas híbridas, cujos enunciados contêm uma mistura das linguagens da comunidade e da ciência, e atividades de associação e separação de linguagens. Ver mais em: http://www.campusvirtual.ufsj. edu.br/mooc/ciencianacomunidade/.
} 
a lado. Porque às vezes, a gente via o conhecimento popular quando a gente clicava naquelas interrogações a gente tinha curiosidade, mas aí passava, logo tinha outra curiosidade, a gente ia ver tudo lá no final. Então, lá no final ficou cansativo. A gente ia lendo: 'É isso, é isso, é isso'. Mas a curiosidade vinha logo de início, mas aí passava e também tinha outra curiosidade e não ia sendo respondida aos poucos. Era respondido de forma direta no final. Então assim, acabou que foi feita uma leitura superficial no final, por ser muita informação, muito conteúdo de uma vez só" (A5d2). Tais ideias, assim como apresentado pelo componente "criação" de "usos", expressam a capacidade de desenvolver abordagens imaginativas, técnicas, artefatos ou conteúdos através da aplicação de habilidades de letramento digital (HINRICHSEN; COOMBS, 2013).

\section{Análise}

A subcategoria crítica diz respeito à percepção do que significa ser 'crítico'. Nesse momento, estamos interessados em entender como o modelo favoreceu o desenvolvimento dessa capacidade. Observamos que os licenciandos significaram-na de diferentes formas. Eles disseram, em alguns momentos, que foram críticos durante as interações e, em outros, reconheceram a necessidade de realizarem uma interação, exploração e uso mais crítico da hipermídia e do DVD. Alguns se referiram ao aprofundamento de algo, opondo-se à superficialidade da exploração das mídias, conforme ocorreu na primeira interação com o DVD e a hipermídia.

Um licenciando disse: "a gente pode falar que antes de ter contato com esse negócio [referindo-se ao modelo], nós analisamos com o olhar mais superficial, depois nós começamos a observar com um olhar mais crítico" (A13i2). Eles também apontaram que ser crítico é o oposto ao que limita, ou seja, como algo que amplia o olhar. Um licenciando disse: "ficamos limitados aos recursos visuais. Pode ser, só. No segundo momento, podemos interagir com a hipermídia com o olhar mais crítico" (A13i2).

Outra perspectiva foi a de que 'ser crítico' é dar uma opinião, 'depreciando' ou 'elogiando', simplesmente. Assim como elogiaram o material, como a música e as animações, também apontaram o que não gostaram. Reclamaram principalmente de um dos efeitos utilizados em uma das cenas do DVD, mas não procuraram conhecer os motivos disso. Outros associaram ser crítico à avaliação. Uma licencianda foi incisiva nessa direção: "Eu acho que o que a gente avançou, principalmente, é o olhar crítico, né. Que agora a gente tá olhando pra hipermídia no sentido de avaliar. E antes a gente tava olhando, tipo brincando. Agora a gente tá olhando com um olhar de quem tá avaliando" (A8i2). Assim, associaram ser crítico à 'profundidade', 'expansividade', 'opinião' e 'análise'. Uma licencianda mencionou a atitude questionadora, de busca pelo que está além das aparências: "Ser mais crítico na leitura que a gente tava fazendo. Pra que que serve, para que que deixou de servir, a fala que que tem a ver. Então assim, é isso nessa parte que a gente avançaria" (A19i2).

É importante observar que os autores Hinrichsen e Coombs (2013) relacionam ser crítico aos aspectos internos (análise e julgamento do conteúdo e aplicação) e externos das tecnologias (posição sobre desenvolvimento, efeitos e relações sociais relacionados). Eles discutem a criticidade também no âmbito do recurso "análise", referindo-se ao fato de que os docentes "[...] precisam ser capazes de aplicar perspectivas críticas, estéticas e éticas para a 
produção e consumo de material digitalizado" (HINRICHSEN; COOMBS, 2013, p. 11, tradução nossa). O recurso desdobra-se em outros componentes, tais como o discernimento, capacidade de julgar, avaliar, escolher, recomendar ou rejeitar e questionar a proveniência, finalidade e impacto das tecnologias digitais. Dessa forma, notou-se que os discentes se viram mais críticos após a segunda interação, principalmente por aprofundarem suas explorações e avaliarem as mídias e suas ações. Entretanto, notamos que eles não questionaram a proveniência, a finalidade ou o impacto das mídias analisadas e a razão de se apresentarem como tais.

\section{Imagens pessoais}

A subcategoria percepção do conhecimento e gosto próprio vincula-se à percepção do conhecimento novo pelos licenciandos, relativo aos assuntos discutidos e analisados e às suas preferências. Na segunda interação com as mídias, eles pararam para pensar sobre as identificações geradas pelo material, os conhecimentos novos aprendidos, o que já sabiam e seus gostos pessoais. Percebemos que se identificaram positiva e negativamente com certos aspectos estéticos das mídias, de acordo com seus gostos pessoais.

Algumas opiniões assemelharam-se, como, por exemplo, sobre o efeito cartoon utilizado no vídeo de Dona Mariinha em uma das cenas do DVD. Uma licencianda disse: "eu tô achando péssimo. Foi horrível essa ideia dessa pessoa fazer um desenho" (A14i1). Mas, houve também quem elogiou: "eu gostei, a imagenzinha eu achei bem pedagógico. Todo colorido" (A10i1). Outra apontou sua percepção do modelo: "esse modelo fez a gente ver que existe esse tipo de conhecimento. Existe mesmo essa questão de avaliar esse desenvolvimento das identidades, a questão da reputação, em cima da hipermídia. A gente não tinha conhecimento disso" ( $\mathrm{A} 5 \mathrm{~d} 2$ ). No recurso imagens pessoais, a ênfase é ter sensibilidade às questões de reputação, identidade e associação dentro de diferentes contextos digitais. (HINRICHSEN; COOMBS, 2013).

Na relação entre os participantes emergiram dados sobre como os integrantes dos grupos se relacionaram uns com os outros e os demais colegas da turma. Para um grupo, a afinidade pareceu ter comprometido as ações, conforme disse um dos componentes: "acho que no nosso caso erramos, porque a gente não tinha afinidade, a gente fazia travado com a hipermídia. A gente ficava assim tipo sem conseguir, porque a gente não sabia como tava o outro" (A22d2). Todavia, apesar de não conversarem sobre tudo em suas interações, eles refletiram sobre o que estavam explorando, conforme o enunciado: "eu acho que às vezes, a gente fez uma análise meio silenciosa, sabe. Tipo assim, eu tava olhando e eu estava pensando na minha cabeça. Mas, a gente poderia ter discutido mais. Um ponto que a gente podia ter melhorado, é ter externado estes pensamentos" (A8i2). Notamos, assim, que a constituição dos grupos determinou a interação entre os participantes e, no segundo grupo, ocorreram mais interações verbais.

Ao expressarem suas opiniões sobre as mídias, notamos que os licenciandos foram levados a construir uma identidade, o que está relacionado à reputação diante do grupo e à expressão deles próprios para os outros. Percebemos isso quando comentaram sobre seus desinteresses e como falariam sobre isso para a turma: "Acho que teve muita falta de interesse. Mas a gente não vai falar isso" (A14i2); "pode ser falado, mas de outra maneira, aliviando um pouco a nossa culpa, claro" (A13i2); "pra mim, não sei. Depois a gente ficou mais interessado, não ficou? Depois a gente ficou mais interessado" (A15i2). Essas falas 
fizeram perceber que 'imagens pessoais' também se relacionam com a construção ou projeção de identidades nos trabalhos coletivos de análise de materiais digitais.

\section{Considerações Finais}

Dentre os efeitos dos cinco recursos do letramento digital crítico nas percepções dos licenciandos sobre suas interações com as mídias em $O$ doce de leite, podemos dizer que o modelo funcionou como uma orientação mais crítica, levou ao direcionamento das ações, e elevou o interesse pelo conteúdo do material analisado. Destacamos as contribuições do modelo para a aquisição de uma visão espacial e pormenorizada das mídias, sugerindo navegar melhor, evitar se perder e prestar maior atenção em seus constituintes, evitando, com isso, ser superficial para desenvolver uma exploração mais completa, principalmente na leitura do código escrito.

Apesar de ter ajudado a organizar o conhecimento para o letramento digital, os licenciandos demonstraram dificuldades em analisar os recursos separadamente, devido à interligação que existe entre eles, característica já apresentada pelo referencial teórico. Uma licencianda afirmou: "a sensação que eu tinha é, às vezes, a gente ter a mesma resposta pra todos" $(\mathrm{A} 5 \mathrm{~d} 2)$. Outro aspecto é que a exploração do modelo pode variar de acordo com os materiais analisados e nem sempre será completamente explorado, o que implica na necessidade de utilizá-lo em análises de diferentes materiais digitais. Para aqueles interessados em utilizar esse referencial em outras experiências, uma dificuldade que tivemos foi a forma como os autores determinam as características de cada componente do modelo e a necessidade de sua simplificação para os estudantes de graduação.

Diante da perspectiva de observação e entendimento, os maiores problemas da intervenção didática proposta tiveram relação com o recurso usos. Embora o formato das ações tenha possibilitado a conscientização sobre a necessidade de manter um constante diálogo com a educação básica, poderíamos ter problematizado as ações iniciais com as mídias tomando esse recurso específico por base. As mídias sobre $O$ doce de leite foram concebidas para inserir e aprofundar saberes da cultura popular nas aulas de química da educação básica e os licenciandos demonstraram limitações em suas propostas de utilizálas.

Em relação à produção de significados, observamos o diálogo com a experiência e o conhecimento prévio, mas o conhecimento químico explicativo encontrou pouca expressão nesse recurso, fazendo perceber a necessidade de propor um direcionamento para aprofundamento. Outra percepção foi que, para os licenciandos menos familiarizados com as tecnologias digitais, houve mais variáveis em movimento e mais habilidades a serem desenvolvidas e o modelo dos cinco recursos agiu como um suporte para isso, demonstrando ganhos para todos.

Em relação à prática formativa, a organização das ações possibilitou trocas, questionamentos, reflexões e autorreflexões sobre como os licenciandos agiram espontaneamente com essas mídias e como os cinco recursos contribuíram para a percepção de suas características operacionais, estruturais, estéticas e éticas, para o desenvolvimento da criticidade e a compreensão de como ocorrem os processos de significação. Tais contribuições, contudo, também se vinculam à intervenção didática realizada e ao material analisado. 
A respeito da integração do letramento digital ao currículo, sugerimos que seja contemplado em mais de uma disciplina dos cursos de licenciatura, utilizando o referencial adotado e outros para análise de suportes e contextos variados, por meio da produção conjunta de conhecimentos e tendo em vista seu deslocamento para as aulas de ciências da educação básica.

No presente texto, embora não tenhamos descrito e analisado mais profundamente as pesquisas realizadas pelos licenciandos, cabe mencionar que seus resultados indicaram a ausência de letramentos digitais em suas formações escolares e acadêmicas e apontaram para o estabelecimento de processos mais colaborativos entre professores e estudantes.

\section{Referências}

BARDIN, L. Análise de conteúdo. Lisboa: Edições 70, 1994.

BARTON, D.; HAMILTON, M. La literacidad entendida como práctica social. In: ZAVALA, V.; NIÑOMURCIA, M.; AMES, P. (org.). Escritura y sociedade: nuevas perspectivas teóricas y etnográficas. Lima: Red para el Desarrollo de las Ciencias Sociales en el Perú, 2004. p. 109-139.

BRASIL. Lei n.13.005, de 25 de junho de 2014. Aprova o plano nacional de educação - PNE e dá outras providências. Diário Oficial da União, Brasília, 26 jun 2014. Disponível em: https://tinyurl.com/ y8v2wzpc. Acesso em: 5 mar. 2019.

BRASIL. Ministério da Educação. Diretrizes curriculares nacionais da educação básica. Brasília: Ministério da Educação, 2013.

BUZATO, M. E. K. Letramentos digitais e formação de professores. In: CONGRESSO IBEROAMERICANO EDUCAREDE: Educação, Internet e Oportunidades, 3., 2006., São Paulo. Atas [...]. São Paulo: Portal Educarede, 2006. p. 1-14.

CORRÊA, H. T. Prefácio. In: TONINI, A. M.; CORRÊA, H. T. (org.). Pacto nacional pela alfabetização na idade certa: letramentos múltiplos e multiletramentos: entre teorias e práticas. Várzea Paulista: MW Comunicação Integrada, 2017. p. 7-10.

COSCARELLI, C. V. Tecnologias para aprender. São Paulo: Parábola Editorial, 2016.

DUDENEY, G.; HOCLY, N.; PEGRUM, M. Letramentos digitais. São Paulo: Parábola Editorial, 2016.

EVOLUÇÃO das tecnologias na educação. 2016. Disponível em: https://tinyurl.com/y75uoetj. Acesso em: 3 mar. 2019.

FAGUNDES, T. B. Os conceitos de professor pesquisador e professor reflexivo: perspectivas de trabalho docente. Revista Brasileira de Educação, Rio de Janeiro, v. 21, n. 65, p. 281-298, 2016. DOI: http://doi.org/gfknqk.

FREEBODY, P.; LUKE, A. Literacies programs: debates and demands in cultural context. Prospect : an Australian Journal of TESOL, Brisbane, v. 5, n. 3, p. 7-16, 1990. Disponível em: https://tinyurl.com/ ydgcpx4q. Acesso em: 20 jun. 2020.

FREITAS, M. T. Letramento digital e formação de professores. Educação em Revista, Belo Horizonte, v. 26, n. 3, p. 335-352, 2010. DOI: http://doi.org/cxcbwb.

GEE, J. P. The new literacy studies: from 'socially situated' to the work of the social. In: BARTON, D.; HAMILTON, M.; IVANIC, R. (org.). Situated literacies: reading and writing in context. London: Routledge, 2000. p. 180-196. 
HINRICHSEN, J.; COOMBS, A. The five resources of critical digital literacy: a framework for curriculum integration. Research in Learning Technology, London, v. 21, p. 1-16, 2013. DOI: http://doi.org/ ggr9dn.

HINRICHSEN, J.; COOMBS, A. The 5 resources model of critical digital literacy. London: University of Greenwich, [2014?]. Disponível em: https://sites.google.com/site/dlframework/. Acesso em: 20 jun. 2020.

MACIEL, F. G.; PASSOS, M. M.; ARRUDA, S. M. Pesquisas em ensino de ciências com metodologia interventiva: o que fazem os pesquisadores da área? Revista Brasileira de Pesquisa em Educação em Ciências, Belo Horizonte, v. 18, n. 2, p. 549-579, 2018. DOI: http://doi.org/d2v9.

MELEIRO, A.; GIORDAN, M. Hipermídia no ensino de modelos atômicos. Química Nova na Escola, São Paulo, n. 10, p. 17-20, 1999. Disponível em: https://tinyurl.com/y9onzs4m. Acesso em: 23 jun. 2020.

OLIVEIRA, C. B.; GONZAGA, A. M. Professor pesquisador - educação científica: o estágio com pesquisa na formação de professores para os anos iniciais. Ciência \& Educação, Bauru, v. 18, n. 3, p. 689-702, 2012. DOI: http://doi.org/d2wb.

RIBEIRO, A. E. Tecnologia digital e ensino: breve histórico e seis elementos para ação. Linguagem \& Ensino, Pelotas, v. 19, n. 2, p. 91-111, 2016. Disponível em: https://tinyurl.com/yafdkv7w. Acesso em: 20 jun. 2020.

RIEDNER, D. D. T.; PISCHETOLA, M. Tecnologias digitais no ensino superior: uma possibilidade de inovação das práticas? Educação, Formação \& Tecnologias, Monte da Caparica, v. 9, n. 2, p. 37-55, 2016. Disponível em: https://tinyurl.com/yc8adgu7. Acesso em: 2 jun. 2020.

SCHNETZLER, R. P. A pesquisa em ensino de química no Brasil: conquistas e perspectivas. Química Nova, São Paulo, v. 25, supl. 1, p. 14-24, 2002. Disponível em: https://tinyurl.com/yd9hhy9u. Acesso em: 22 jun. 2020.

SCHNETZLER, R. P. A pesquisa no ensino de química e a importância da Química Nova na Escola. Química Nova na Escola, São Paulo, v. 20, n. 20, p. 49-54, 2004. Disponível em: https://tinyurl.com/ ydecwsvu. Acesso em: 23 maio 2020.

SCHNETZLER, R. P.; ARAGÃO, R. M. R. Importância, sentido e contribuições de pesquisas para o ensino de química. Química Nova na Escola, São Paulo, v. 1, n. 1, p. 27-31, 1995. Disponível em: https://tinyurl.com/y7w2dphw. Acesso em: 23 maio 2020.

SOARES, M. Letramento: um tema em três gêneros. Belo Horizonte: Autêntica, 2002.

STREET, B. Los nuevos estudios de literacidad. In: ZAVALA, V.; NIÑO-MURCIA, M.; AMES, P. (org.). Escritura y sociedad: nuevas perspectivas teóricas y etnográficas. Lima: Red para el Desarrollo de las Ciencias Sociales en el Perú, 2004. p. 81-109. 